\title{
On the multi-fractal characteristics of the ULF geomagnetic field before the 1993 Guam earthquake
}

\author{
F. Masci \\ Istituto Nazionale di Geofisica e Vulcanologia, L'Aquila, Italy \\ Correspondence to: F. Masci (fabrizio.masci@ingv.it)
}

Received: 11 April 2012 - Revised: 1 September 2012 - Accepted: 4 September 2012 - Published: 29 January 2013

\begin{abstract}
Ida et al. (2005) document significant changes in the multi-fractal parameters of the ULF geomagnetic field $H$ component starting about one month before the 1993 Guam earthquake. According to the authors, these multi-fractal signatures can be considered as precursory signals of the Guam earthquake. As a consequence, they conclude that the multifractal analysis may have an important role in the development of short-term earthquake prediction capabilities. Since this and other similar reports have motivated the idea that earthquake prediction based on electromagnetic precursory signals may one day become a routine technique, the presumed precursors need to be validated through independent datasets. In this review the seismogenic origin of the multifractal magnetic signatures documented by Ida et al. (2005) before the 8 August 1993 Guam earthquake is seriously put into question. By means of the geomagnetic $\Sigma K_{\mathrm{p}}$ index, it is demonstrated that these multi-fractal parameter changes are normal signals induced by the variation of the global geomagnetic activity level.
\end{abstract}

\section{Introduction}

Several researchers consider the investigation of the ultralow frequency (ULF: $0.001-10 \mathrm{~Hz}$ ) geomagnetic field signals as a useful tool for detecting magnetic earthquake precursors. However, since previous studies do not show strong evidence of correlation between the presumed magnetic precursors and seismic events, many scientists do not agree that these signals are really related to the earthquake occurrence. As a consequence, these researchers seriously put into question previous observations of magnetic ULF earthquake precursors and have published their findings (see Campbell, 2009; Masci, 2010, 2011a, b, 2012a, b, c; Thomas et al., 2009a, b) giving rise to an intense re-examination process of controversial scientific claims (see also Fraser-Smith et al., 2011; Masci, 2012d; Thomas et al., 2012).

Different methods were used to isolate possible seismogenic magnetic disturbances in the ULF frequency band. These methodologies include fractal analysis as well. Modern theories describe earthquakes as chaotic phenomena (e.g. Bak and Tang, 1989) suggesting that the Earth's crust behaves as a self-organized critical (SOC) system. As a consequence, since the SOC state has a fractal organization, some authors (e.g. Hayakawa et al., 1999) maintain that fractal signatures related to the earthquake preparation process should also be found in the electromagnetic signals which could be possibly generated by the seismic activity. Consequently, according to these authors, the investigation of the fractal characteristics of the geomagnetic field could provide information on the earthquake preparation process. Several reports (see e.g. Hayakawa et al., 1999, 2000; Smirnova et al., 2001; Smirnova and Hayakawa 2007; Gotoh et al., 2003, 2004; Ida and Hayakawa, 2006) by means of mono-fractal analysis document the observation of precursory signatures in the ULF geomagnetic field before the occurrence of strong earthquakes. According to Masci (2010), these authors reach their conclusions in an oversimplified manner failing to examine the influence of other possible ULF sources as well as the geomagnetic activity which is the main source of ULF disturbances (McPherron et al., 2005). The study by Masci (2010) demonstrates that the changes of the monofractal characteristics of the geomagnetic field components, which previous reports have claimed to be related to seismogenic signals, were normal disturbances induced by the variation of the global geomagnetic activity level. More recently, Masci and Di Persio (2012) investigate the possible occurrence of seismogenic signals in the magnetic field data from 
the Geomagnetic Observatory of L'Aquila which is located only $6 \mathrm{~km}$ from the epicentre of the $M_{\mathrm{w}}=6.36$ April 2009 L'Aquila earthquake. They found no seismogenic fractal signature but only a close correlation between the geomagnetic field fractal dimension and the global geomagnetic activity level, before and after the earthquake.

In the present paper, I investigate the multi-fractal signatures in the ULF magnetic field which Ida et al. (2005) claim to be related to the Guam earthquake.

\section{Discussion}

On 8 August 1993, an $M_{\mathrm{w}}=7.7$ earthquake occurred offshore the island of Guam. Several papers (see e.g. Hayakawa et al., 1996; 1999; Ida and Hayakawa, 2006; Smirnova et al., 2001; Smirnova and Hayakawa, 2007; Varlamov and Smirnova, 2008) document the observation of precursory signals of this earthquake. The presumed precursors of the Guam earthquake can be essentially reassumed in the increase of the fractal dimension of the geomagnetic field components and in the change of the ratio between the integrated power, in a fixed frequency band, of the vertical component and the horizontal components of the geomagnetic field, the so-called polarization ratio. However, recently Masci (2010, 2011a, b) and Thomas et al. (2009b) have demonstrated that these presumed precursors of the Guam earthquake were normal disturbances closely related to changes of the global geomagnetic level and then not induced by the seismic activity.

Ida et al. (2005), hereafter cited as IDA, performed multifractal detrended fluctuation analysis (MFDFA) of ULF geomagnetic field data from the Guam observatory which is located $65 \mathrm{~km}$ away from the epicentre of the 1993 Guam earthquake. The authors document seismogenic changes in the multi-fractal parameters of the geomagnetic field $H$ component starting about one month before the earthquake. As Thomas et al. (2012) emphasize, these kinds of reports have motivated many researchers to study in depth the possible occurrence of earthquake precursors as well as to develop physical models to explain their generation. Thus, the results of these publications must be carefully checked.

Nonstationary time series of many physical systems, including the geomagnetic field (Hongre et al., 1999), exhibit different scaling properties which can be characterized by means of multi-fractal analysis. MFDFA is a useful tool to investigate the degree of multi-fractality of these time series. Leaving aside a full description of the MFDFA (see Kantelhardt et al., 2002; Ida et al., 2005 for details), I will briefly touch on the multi-fractal parameters investigated by IDA. Figure 3 by IDA (here not reported) shows an example of the two curves that characterize the multi-fractal behaviour of a nonstationary time series: the generalized dimension $D(q)$, where $q$ can take any real value, and the multi-fractal spectrum $f(\alpha)$ which represents the dimension of each subset of the series characterized by the scaling exponent $\alpha$ (where $\alpha$ is the Hölder exponent). For a mono-fractal time series, $D(q)$ is constant for any value of $q$, whereas $f(\alpha)$ reduces to a point.

The study by IDA investigates the changes of the following MFDFA parameters of the geomagnetic field $H$ component: $\alpha_{\min }, \alpha_{\max }, w=\left(\alpha_{\max }-\alpha_{\min }\right), f_{\max }, \alpha\left(f_{\max }\right)$, and $\Delta=\left(w / f_{\max }\right) \cdot \alpha_{\min }$ and $\alpha_{\max }$ are the minimum and the maximum values assumed by the scaling exponent $\alpha$, respectively; $w$ is the width of the spectrum; $f_{\max }$ is the maximum value of $f(\alpha)$, and $\alpha\left(f_{\max }\right)$ is the corresponding scaling exponent, i.e. the dominant scaling exponent; $\Delta$ quantifies the non-uniformity of the spectrum. According to IDA, during the period from about one month to few days before the Guam earthquake, the multi-fractal parameters of the geomagnetic field $H$ component show the following behaviour:

1. $w$ shows a significant increase; the increase is related to a significant decrease of $\alpha_{\min }$ since $\alpha_{\max }$ does not show any evident change;

2. $\alpha\left(f_{\max }\right)$ seems to show no evident change, but $f_{\max }$ decreases before the earthquake;

3. the most pronounced effect can be found in the nonuniformity factor $\Delta$ which shows a significant increase about a month before the earthquake and remains at a high value until few days before the earthquake;

4. the increase of $\Delta$ seems not to be related with the geomagnetic activity since it occurs during a geomagnetic quiet period (see the Ap index time series reported in the upper panel of Fig.1).

The authors also maintain that the capacity dimension $D(0)$ (which corresponds to the mono-fractal dimension in the MFDFA) shows a significant increase during the period before the earthquake. According to IDA the increase of $D(0)$ supports the results of previous studies which investigate the fractal characteristics of the geomagnetic field before the Guam earthquake (see e.g. Hayakawa et al., 1999; Ida and Hayakawa, 2006). Concerning this point, I would like to emphasize that Masci (2010) demonstrated that the increase of the fractal dimension, which occurred some months before the occurrence of the Guam earthquake (see Hayakawa et al., 1999), is well correlated with a geomagnetic activity decrease. Thus, this increase of the fractal dimension was part of normal global magnetic field changes driven by solarterrestrial interactions and it was not related to the preparation process of the earthquake. IDA conclude that, since the MFDFA provides evidence of ULF precursory signals of the Guam earthquake, the multi-fractal analysis appears to be of great potential in the short-term earthquake prediction. Let me say that, to be useful, earthquake prediction requires trustworthy precursors. Any potential anomaly, before able to be considered as a reliable earthquake precursor, should be excluded as a random anomaly or as an anomaly induced by other possible sources, both natural and artificial. In my 


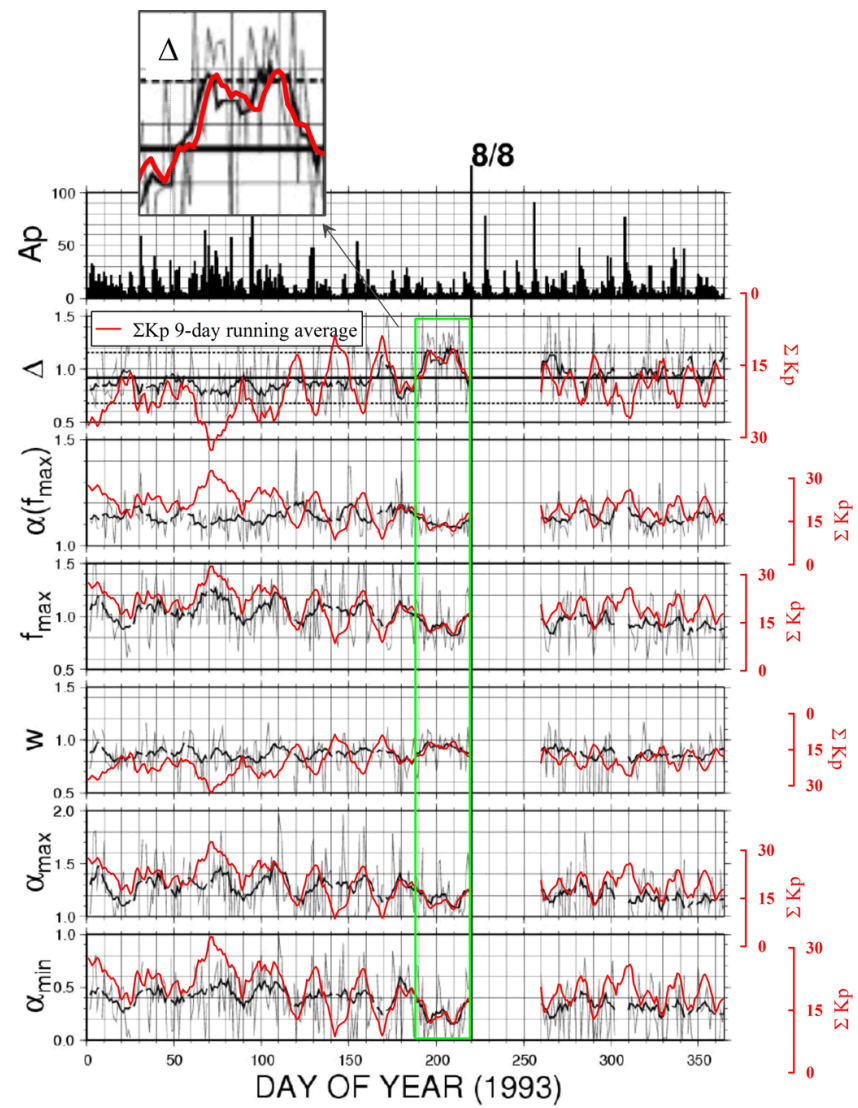

Fig. 1. A reproduction of Fig. 4 by Ida et al. (2005). From the top: geomagnetic Ap index and multi-fractal parameters $\Delta, \alpha\left(f_{\max }\right)$, $f_{\max }, w, \alpha_{\max }$, and $\alpha_{\min }$ daily values (thin black lines) and 9-day running average (thick black lines) time series. The area bounded by the green line highlights the period of the occurrence of the presumed precursors of Guam earthquake. $\Sigma K_{\mathrm{p}}$ 9-day running average (red line) is superimposed onto each multi-fractal parameters panel. An enlarged view of $\Delta$ before the Guam earthquake is reported at the top of the figure. See text for details.

opinion the authors have underestimated the influence of the global geomagnetic activity. They excluded any correlation between the changes of the geomagnetic field multi-fractal parameters and the geomagnetic activity since the presumed multi-fractal precursors occurred during a geomagnetic quiet period. This is an oversimplified assumption since we must not consider the level of the geomagnetic activity but its variations which induce changes in several magnetic parameters as well as in the fractal characteristics of the geomagnetic field (see also Masci 2010, 2011a).

Figure 1 shows the time series of the MFDFA parameters reported by IDA as daily and 9-day running average values. The area bounded by the green line highlights the period of the occurrence of presumed precursory signatures. Here the 9-day running average of the planetary geomagnetic $\Sigma K_{\mathrm{p}}$ index has been superimposed onto each panel of the original view. Now, we put our attention to the last period (about

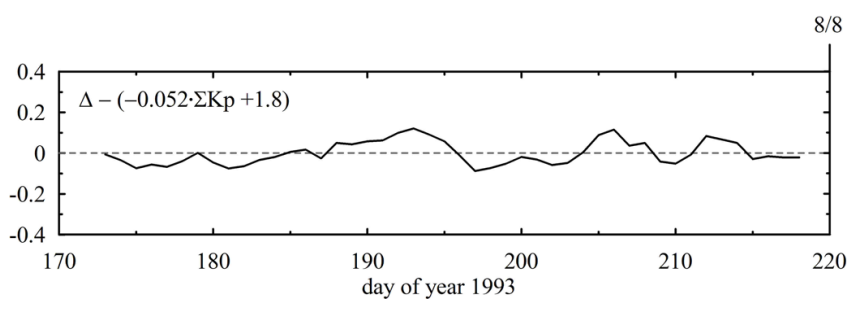

Fig. 2. Residual time series of the linear relationship between the 9-day running averages of $\Delta$ and $\Sigma K_{\mathrm{p}}$ during the period of time before the Guam earthquake.

6 weeks) before the earthquake date. An enlarged view of the non-uniformity factor $\Delta$ during this period of time is reported on the top of Fig. 1. Contrary to the opinion of IDA, before the Guam earthquake, it is clearly evident that there is influence of the geomagnetic activity on the fractal characteristics of the magnetic field since each multi-fractal parameter shows a close correlation with $\Sigma K_{\mathrm{p}}$. This correlation is positive for $\alpha_{\min }, \alpha_{\max }, f_{\max }$, and $\alpha\left(f_{\max }\right)$, negative for $w$ and $\Delta$. The good correspondence between the variations of the multi-fractal parameters and $\Sigma K_{\mathrm{p}}$ demonstrates that, before the Guam earthquake, the changes of these parameters were induced by variations of the geomagnetic activity level. During this period, $\Delta$ and $w$ show an initial increase, more evident in $\Delta$, lasting about two weeks. This increase is followed by a period of time in which $\Delta$ and $w$ remain almost stable and by a decrease during the last ten days before the earthquake. On the contrary, $\alpha_{\min }, \alpha_{\max }, f_{\max }, \alpha\left(f_{\max }\right)$ show the opposite behaviour. The initial increase of $\Delta$ (and $w$ ) suggests that the system (i.e. the geomagnetic field) has a transition from a more ordered state toward a less ordered state. This finding is confirmed by the corresponding decrease of $\Sigma K_{\mathrm{p}}$, which indicates a decrease of the geomagnetic activity. This means that the magnetosphere evolves toward a lower degree of organization (see e.g. Balasis et al., 2009). The transition of the geomagnetic field towards a less ordered state is further supported by the increase of the capacity dimension $D(0)$ (see also Ida and Hayakawa, 2006) since a higher fractal dimension means a lower degree of organization. On the contrary, after the period in which the MFDFA parameters are almost stable, the decrease of $\Delta$, and the corresponding $\Sigma K_{\mathrm{p}}$ increase, suggests that the magnetosphere evolves towards a higher degree of organization. In summary, during the period before the Guam earthquake, the changes of the fractal characteristics of the geomagnetic field $H$ component seem to be closely related to variations of the geomagnetic activity level.

As further investigation, I digitalized the 9-day running average of $\Delta$ during the period of time before the Guam earthquake. Secondly, the linear relationship and the correlation coefficient between the 9-day running averages of $\Delta$ and $\Sigma K_{\mathrm{p}}$ were calculated. The correlation coefficient is 0.92 , whereas the linear relationship is $\Delta=\left(-0.052 \times \Sigma K_{\mathrm{p}}+1.8\right)$. 
Figure 2 shows the linear residual time series. Here we see that on average the residual time series is mainly flat (with a small oscillation around zero) and does not show any clear anomalous signature. Bearing in mind these findings, we can undoubtedly affirm that, before the Guam earthquake, the behaviour of the non-uniformity factor $\Delta$ was well-correlated with the geomagnetic activity level; therefore, the changes of $\Delta$ cannot be related to the preparation process of the $8 \mathrm{Au}-$ gust 1993 earthquake.

On the other hand, it is also evident from Fig. 1 that the correlation between the multi-fractal parameters and $\Sigma K_{\mathrm{p}}$ fails during several periods of time. In any case this does not mean that the lack of correspondence comes from seismogenic processes. As pointed out by Masci (2011a, 2012a), since the $\Sigma K_{\mathrm{p}}$ index is representative of the geomagnetic field average disturbances over planetary scale, we should not expect that a good correlation between a ULF parameter of the geomagnetic field (in this case the multi-fractal parameters) and the geomagnetic index will exist always and everywhere over long time range. On the contrary, if a close correlation between changes of a ULF parameter of the geomagnetic field and $\Sigma K_{\mathrm{p}}$ exists during a period of time, this indicates that these changes are part of normal global geomagnetic field variations driven by solar-terrestrial interactions and cannot be described as earthquake-related signals. In summary, this paper shows that, before the Guam earthquake, the changes of the multi-fractal characteristics of the geomagnetic field $H$ component are normal solar-driven variations.

\section{Conclusions}

The study by Masci (2010) has demonstrated that the monofractal precursory signatures, which previous papers claimed to be related to strong earthquakes including the $8 \mathrm{Au}-$ gust 1993 Guam earthquake, are actually induced by changes of the geomagnetic activity level driven by solar-terrestrial interactions. Here, the origins of changes in the multi-fractal parameters of the geomagnetic field $H$ component, which were considered by Ida et al. (2005) as precursors of the Guam earthquake, are investigated. This paper seriously puts into question the findings of Ida et al. (2005) showing that the multi-fractal signatures are actually normal signals induced by variations of the global geomagnetic activity level. In conclusion, this paper and the results by Masci (2010) demonstrate that the (mono- and multi-)fractal analysis of the geomagnetic field cannot be considered as a useful tool to study the occurrence of magnetic precursors of earthquakes.
Acknowledgements. The author wishes to thank Jeremy N. Thomas and two anonymous reviewers for their useful comments. I am also grateful to Kyoto World Data Center for Geomagnetism (http://swdcwww.kugi.kyoto-u.ac.jp/) which provided the $\Sigma K_{\mathrm{p}}$ index time series.

Edited by: M. E. Contadakis

Reviewed by: two anonymous referees

\section{References}

Bak, P. and Tang, C.: Earthquakes as self-organized critical phenomenon, J. Geophys. Res., 94, 15635-15637, doi:10.1029/JB094iB11p15635, 1989.

Balasis, G., Daglis, I. A., Papadimitriou, C., Kalimeri, M., Anastasiadis, A., and Eftaxias, K.: Investigating dynamical complexity in the magnetosphere using various entropy measures, J. Geophys. Res., 114, A00D06, doi:10.1029/2008JA014035, 2009.

Campbell, W. H.: Natural magnetic disturbance fields, not precursors, preceding the Loma Prieta earthquake, J. Geophys. Res., 114, A05307, doi:10.1029/2008JA013932, 2009.

Fraser-Smith, A. C., McGill, P. R., and Bernardi, A.: Comment on "Natural magnetic disturbance fields, not precursors, preceding the Loma Prieta earthquake" by Wallace H. Campbell, J. Geophys. Res., 116, A08228, doi:10.1029/2010JA016379, 2011.

Gotoh, K., Hayakawa, M., and Smirnova, N.: Fractal analysis of the ULF geomagnetic data obtained at Izu Peninsula, Japan in relation to the nearby earthquake swarm of June-August 2000, Nat. Hazards Earth Syst. Sci., 3, 229-236, doi:10.5194/nhess-3229-2003, 2003.

Gotoh, K., Hayakawa, M., Smirnova, N. A., and Hattori, K.: Fractal analysis of seismogenic ULF emissions, Phys. Chem. Earth, 29, 419-424, doi:10.1016/j.pce.2003.11.013, 2004.

Hayakawa, M., Kawate, R., Molchanov, O. A., and Yumoto, K.: Results of ultra-low-frequency magnetic field measurements during the Guam earthquake of 8 August 1993, Geophys. Res. Lett., 23, 241-244, doi:10.1029/95GL02863, 1996.

Hayakawa, M., Ito, T., and Smirnova, N.: Fractal analysis of ULF geomagnetic data associated with the Guam earthquake on August 8, 1993, Geophys. Res. Lett., 26, 2797-2800, doi:10.1029/1999GL005367, 1999.

Hayakawa, M., Itoh, T., Hattoti, K., and Yumoto, K.: ULF electromagnetic precursors for an earthquake at Biak, Indonesia on February 17, 1996, Geophys. Res. Lett., 27, 1531-1534, doi:10.1029/1999GL005432, 2000.

Hongre, L., Sailhac, P., Alexandrescu, M., and Dubois, J.: Nonlinear and multifractal approaches of the geomagnetic field, Phys. Earth Planet. Inter., 110, 157-190, doi:10.1016/S00319201(98)00133-2, 1999.

Ida, Y. and Hayakawa, M.: Fractal analysis for the ULF data during the 1993 Guam earthquake to study prefracture criticality, Nonlin. Processes Geophys., 13, 409-412, doi:10.5194/npg-13409-2006, 2006.

Ida, Y., Hayakawa, M., Adalev, A., and Gotoh, K.: Multifractal analysis for the ULF geomagnetic data during the 1993 Guam earthquake, Nonlin. Processes Geophys., 12, 157-162, doi:10.5194/npg-12-157-2005, 2005.

Kantelhardt, J. W., Zschiegner, S. A., Koscielny-Bunde, E., Bunde, A., Havlin, S., and Stanley, H. E.: Multifractal detrended fluctua- 
tion analysis of nonstationary time series, Physica A, 316, 81-91, doi:10.1016/S0378-4371(02)01383-3, 2002.

Masci, F.: On claimed ULF seismogenic fractal signatures in the geomagnetic field, J. Geophys. Res., A10236, doi:10.1029/2010JA015311, 2010.

Masci, F.: On the seismogenic increase of the ratio of the ULF geomagnetic field components, Phys. Earth Planet. Inter., 187, 1932, doi:10.1016/j.pepi.2011.05.001, 2011a.

Masci, F.: Brief communication "On the recent reaffirmation of ULF magnetic earthquakes precursors", Nat. Hazards Earth Syst. Sci., 11, 2193-2198, doi:10.5194/nhess-11-2193-2011, $2011 \mathrm{~b}$.

Masci, F.: Comment on "Ultra Low Frequency (ULF) European multi station magnetic field analysis before and during the 2009 earthquake at L'Aquila regarding regional geotechnical information" by Prattes et al. (2011), Nat. Hazards Earth Syst. Sci., 12, 1717-1719, doi:10.5194/nhess-12-1717-2012, 2012a.

Masci, F.: Comment on "Possible association between anomalous geomagnetic variations and the Molise Earthquakes at Central Italy during 2002" by Takla et al. (2011), Phys. Earth Planet. Inter., 202-203, 92-94, doi:10.1016/j.pepi.2012.02.006, 2012b.

Masci, F.: On the ULF magnetic ratio increase before the 2008 Iwate-Miyagi Nairiku earthquake by Hirano and Hattori (2011), J. Asian Earth Sci., 56, 258-262, doi:10.1016/j.jseaes.2012.05.020, 2012c.

Masci, F.: The study of ionospheric anomalies in Japan area during 1998-2010 by Kon et al.: An inaccurate claim of earthquake-related signatures?, J. Asian Earth Sci., 57, 1-5, doi:10.1016/j.jseaes.2012.06.009, 2012d.

Masci, F. and Di Persio, M.: Retrospective investigation of geomagnetic field time-series during the 2009 L'Aquila seismic sequence, Tectonophysics, 530-531, 310-317, doi:10.1016/j.tecto.2012.01.008, 2012.
McPherron, R. L.: Magnetic pulsations: their sources and relation to solar wind and geomagnetic activity, Surv. Geophys., 26, 545592, doi:10.1007/s10712-005-1758-7, 2005.

Smirnova, N. A. and Hayakawa, M.: Fractal characteristic of ground-observed ULF emissions in relation to geomagnetic and seismic activities, J. Atmos. Sol-Terr. Phys., 69, 1833-1841, doi:10.1016/j.jastp.2007.08.001, 2007.

Smirnova, N., Hayakawa, M., Gotoh, K., and Volobuev, D.: Scaling characteristics of ULF geomagnetic fields at the Guam seismoactive area and their dynamics in relation to the earthquake, Nat. Hazards Earth Syst. Sci., 1, 119-126, doi:10.5194/nhess-1-1192001, 2001.

Thomas, J. N., Love, J. J., and Johnston, M. J. S.: On the reported magnetic precursor of the 1989 Loma Prieta earthquakes, Phys. Earth Planet. Inter., 173, 207-215, doi:10.1016/j.pepi.2008.11.014, 2009a.

Thomas, J. N., Love, J. J., Johnston, M. J. S., and Yumoto, K.: On the reported magnetic precursor of the 1993 Guam earthquake, Geophys. Res. Lett., 36, L16301, doi:10.1029/2009GL039020, 2009b.

Thomas, J. N., Love, J.J., Komjathy, A., Verkhoglyadova, O. P., Butala, M., and Rivera, N.: On the reported ionospheric precursor of the 1999 Hector Mine, California earthquake, Geophys. Res. Lett., 39, L06302, doi:10.1029/2012GL051022, 2012.

Varlamov, A. A. and Smirnova, N. A.: Peculiarities of the ULF emission fractal characteristics obtained at the stations of 219 GM, Proceedings of the 7th International Conference "Problems of Geocosmos", St. Petersburg, Russia, 26-30 May 2008, 487491, 2008. 